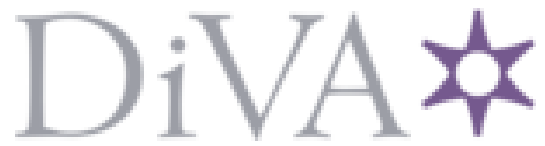

http://www.diva-portal.org

Postprint

This is the accepted version of a paper presented at IEEE Frontiers in Education Conference (FIE).

Citation for the original published paper:

Nordén, L-Å., Mannila, L., Pears, A. (2017)

Development of a self-efficacy scale for digital competences in schools.

In:

https://doi.org/10.1109/FIE.2017.8190673

N.B. When citing this work, cite the original published paper.

Permanent link to this version:

http://urn.kb.se/resolve?urn=urn:nbn:se:uu:diva-337184 


\section{Development of a self-efficacy scale for digital competences in schools}

\author{
Lars-Åke Nordén \\ Department of Information Technology \\ Uppsala University \\ Email:1ln@it.uu.se
}

\author{
Linda Mannila \\ Department of Computer \\ and Information Science \\ Linköping University \\ Email:linda.mannila@liu.se
}

\author{
Arnold Pears \\ Department of Information Technology \\ Uppsala University \\ Email:arnoldp@it.uu.se
}

\begin{abstract}
As computer science enters the school curricula in an increasing number of countries, teachers must prepare to integrate digital competences into their teaching. This integration is a moving target where new methods, tools and applications appear and disappear at such rates that teachers must have confidence to independently and continuously explore what is new, what is relevant and how to plan their pedagogic activities to include digital competences. In this context approaches which can be used to study self-efficacy in digital competences among school teachers are desperately needed. With such a tool in place, we can make a baseline study and then follow teachers over time to measure changes in their self-efficacy, the cause of these changes and learn how to build their digital competence selfefficacy in different ways. The same tool can also be used to measure the self-efficacy in other populations, e.g., students in teacher training programs to ensure that they obtain an adequate self-efficacy in digital competences during their studies.

This paper describes the development of a self-efficacy scale in digital competences, based on the DigiComp 2.0 framework definition of digital competence. The tool focuses predominantly on digital competences relevant for teachers in school years K-9.
\end{abstract}

\section{INTRODUCTION}

With the introduction of computing into K-9 curricula a plethora of research questions arise. One of the most important of these is how to approach the challenge of scaffolding the educational activities of a very large body of teachers, ranging over many subjects and education levels, who are suddenly required to introduce and integrate computing skills and digital competences into their teaching. Concerns have been raised in many countries about how teachers in different subjects will be able to gain relevant knowledge within computing to such an extent that they can include it in their own teaching practice. A complicating factor is that computing is a moving target where new methods, tools and applications appear and disappear at such rates that teachers simply must gain confidence to on their own continuously explore what is new, what is relevant and how to plan their pedagogic activities to include digital competences. What is needed for the future are teachers who can be independent, confident and equipped with lifelong learning skills within the area of computing.

Self-efficacy beliefs will determine how long individuals will persevere and how resilient they will be in the face of difficulty. A low self-efficacy is more likely to result in less persistence and ultimately, failure to complete the task at hand. The higher the sense of efficacy, the greater the effort, persistence, and resilience. [10], [21]. These are factors that are crucial for problem solving in computing, selfregulated learning, and lifelong learning. There are also studies indicating that teachers with high self-efficacy positively affect student learning and building of new competences [12], [17], [18]. These are arguments to why strong self-efficacy in digital competences becomes a necessity in order for teachers to operate within an evolving curriculum that includes computing and digital competences.

This paper develops and validates items of a self-efficacy scale for assessing the digital competence of K-9 teachers. The scale is based upon skills and capabilities defined by the digital competence framework version 2.0 (DigiComp 2.0) which was developed within the European Commission. This framework is influential in how computing and digital competences are viewed in national K-9 curricula within the European Union (EU), but can also be considered to be relevant to countries outside the EU. The items included in the scale are directly related to the key dimensions of the DigiComp 2.0 framework.

The rest of the paper is organized as follows. We begin by presenting the DigComp framework and how digital competence has been introduced into the national curricula of four European countries: England, Estonia, Finland and Sweden. Next we describe the theory underlying the notion of selfefficacy, and approaches to assessing it. We then present the methodology used in developing the instrument as well as the resulting items. We conclude the paper with a discussion of the scale and its implications and some ideas for future work.

\section{Digital COMPetence in SChools}

As a consequence of the increasing digitalization of our society, digital competence has become an important concept in both general strategy documents and school curricula. The EU has developed a framework for digital competence (DigComp 2.0) identifying five key competence areas: 1) information and data literacy, 2) communication and collaboration, 3) digital content creation, 4) safety and 5) problem solving. Each competence area is accompanied by 3-6 competences, describing the skills and knowledge seen as essential for the component at hand (Table I) [4]. 
TABLE I

LISTING OF COMPETENCES INCLUDED IN THE EU DIGCOMP 2.0 FRAMEWORK.

\begin{tabular}{|c|c|}
\hline Competence area & Competence \\
\hline \multirow{3}{*}{ Information and data literacy } & 1.1 Browsing, searching and filtering data, information and digital content \\
\hline & 1.2 Evaluating data, information and digital content \\
\hline & 1.3 Managing data, information and digital content \\
\hline \multirow{6}{*}{ Communication and collaboration } & 2.1 Interacting through digital technologies \\
\hline & 2.2 Sharing through digital technologies \\
\hline & 2.3 Engaging in citizenship through digital technologies \\
\hline & 2.4 Collaborating through digital technologies \\
\hline & 2.5 Netiquette \\
\hline & 2.6 Managing digital identity \\
\hline \multirow{4}{*}{ Digital content creation } & 3.1 Developing digital content \\
\hline & 3.2 Integrating and re-elaborating digital content \\
\hline & 3.3 Copyright and licenses \\
\hline & 3.4 Programming \\
\hline \multirow{4}{*}{ Safety } & 4.1 Protecting devices \\
\hline & 4.2 Protecting personal data and privacy \\
\hline & 4.3 Protecting health and well-being \\
\hline & 4.4 Protecting the environment \\
\hline \multirow{4}{*}{ Problem solving } & 5.1 Solving technical problems \\
\hline & 5.2 Identifying needs and technological responses \\
\hline & 5.3 Creatively using digital technologies \\
\hline & 5.4 Identifying digital competence gaps \\
\hline
\end{tabular}

Many countries worldwide have revised or are in the process of revising their school curricula in order to include for instance programming and digital citizenship skills [1], [9]. There is no standardized terminology, as terms used include, for instance, computing, computational thinking, programming, coding and digital competence. In a survey of computing in basic education in 21 European countries, developing students' digital competence was listed as the main reason for the curriculum changes by almost all (19/21) countries [1].

We briefly describe the curricula in four European countries: England, where Computing was introduced as a new subject in 2014; Estonia, where a specialized program on digital competence has been in place since 2012; Finland, where a new curriculum for basic education including digital competence is being implemented in grades 1-9 and Sweden, where the national curricula recently was revised in order to better meet the requirements of the digitalized society.

In England, the subject ICT was replaced by Computing in fall 2014. Computing is comprised of three main parts: digital literacy, computer science and information technologies. According to the curriculum (REF) the main learning objectives of tuition in Computing are for students to be able to:

- understand and apply the fundamental principles and concepts of computer science, including abstraction, logic, algorithms and data representation

- analyse problems in computational terms, and have repeated practical experience of writing computer programs in order to solve such problems

- evaluate and apply information technology, including new or unfamiliar technologies, analytically to solve problems

- be responsible, competent, confident and creative users of information and communication technology

Computing education starts in grade 1 (age 5) and England is one of the few countries that include computer science as a subject of its own.
In Estonia, the organization HITSA (The Information Technology Foundation for Education) supports the introduction and use of ICT in education. According to HITSA [8] the Estonian national curriculum describes digital competence as the

ability to cope in the technological world, understand technology trends and the connections between technology and other scientific achievements; to acquire technological literacy for age-appropriate, creative and innovative use of technology tools, integrating thinking with manual activities; to analyse opportunities and risks associated with the implementation of technology; to comply with the requirements for intellectual property protection; to solve problems by integrating thinking with manual activities and carry out ideas purposefully; to cope with household chores and eat healthy."

The Estonian government has given HITSA the task of ensuring that all students are given the possibility to acquire an adequate level of digital competence necessary for both everyday life and further studies. The ProgeTiger program has been initiated as a means of supporting this goal in practice, by designing and offering activities for introducing three themes (engineering sciences, design and technology, and information and communications technology) at different levels of education.

In Finland, digital competence was introduced in the national curriculum for primary education (grades 1-9) in 2014 and this curriculum is currently being implemented [7]. Digital competence is an interdisciplinary trait throughout all grades and includes programming as an integrated element, with particular focus on the subjects mathematics and craft. The general description states that information technology should be used systematically in all subjects and grades, while students should develop their digital competence in four main 
areas: they

- learn to understand central concepts and principles for how digital tools are used and how they work. They are given the opportunity to develop their digital competence in practice while creating their own artifacts.

- are guided in using digital tools in a responsible, ergonomic and safe manner.

- learn to use digital tools for looking up information as well as in exploratory and creative work.

- get experience and training in using digital tools for communicating and building networks.

In 2015, the Swedish government gave the National Agency for Education the task to revise the current K-12 curricula, placing a particular focus on digital competence and programming. In April 2017 the suggested revision for grades 1-9 was approved by the government and it came into force in July 2017, but will not be mandatory until fall 2018. The main goals were added to the section describing the mission of Swedish basic education:

School should stimulate students' creativity, curiosity and self-confidence, as well as the will to try and implement ideas and solve problems. Students should have the opportunity to take initiative and responsibility as well as develop their skills to work both independently and together with others. School should contribute to students development of an understanding for how the digitalization affects individuals and the development of our society. All students should have the opportunity to develop their skills in using digital technology. They should also be given the opportunity to develop a critical and responsible attitude towards digital technology, in order to appreciate the opportunities and understand risks of these technologies, as well as equipping learners to evaluate information. Education should thus give students the possibility to develop their digital competence and an entrepreneurial attitude.

Some examples of how this is to be accomplished within different subjects include:

- integrating programming into the subjects mathematics and technology, and

- emphasising the role and impact of the increased digitalization on our society and our everyday life is in the teaching of social sciences and religion.

Moreover, smaller additions have been made to other subjects, such as the introduction of digital technologies in craft, modeling and simulations in science and geographical information systems (GIS) in geography.

Similar changes can be seen in the curricula of other countries as well. The new content naturally places new requirements on teachers, for whom it is no longer sufficient to know how to use digital tools and technology, as they also need to understand how technology works as well as the impact it has on the lives of individuals and the structure and operation of our society. In addition to being digitally competent as individuals, teachers also need pedagogical and didactic skills which equip them to teach digital competences effectively. The European Framework for the Digital Competence of Educators (DigCompEdu) aims at identifying a specific set of competences focusing on teachers' professional activities [22]. This is closely related to the ISTE Teacher Standards published by the International Society for Technology in Education (ISTE) [14].

\section{SELF-EFFICACY}

Self-efficacy theory is used within several domains concerning education, training or other activities where a person is to attain a new or develop a higher level of skill. Selfefficacy is defined as the belief in personal agency, for instance one's ability to successfully perform a particular behavior or task [6]. Bandura discusses self-efficacy in terms of belief in one's capabilities to organize and execute the course of action required to attain a goal [2]. Self-efficacy beliefs exert a palpable influence on behavior, in particular how long individuals persevere when confronted with difficult tasks and how resilient they will be in the face of difficulty or failure. A low self-efficacy is more likely to result in less persistent efforts in relation to a task, and may ultimately result in failure to complete the task at hand. Attainment of a high sense of self-efficacy is at least as important as possessing the skills themselves. Studies have shown that a person that lacks a certain skill still can complete a task requiring that skill successfully if their self-efficacy regarding the skill is high. Self-efficacy beliefs are also malleable and affect a person's intellectual performance.

Research on teacher self-efficacy indicate a positive correlation between teacher self-efficacy and students' motivation, achievements and building of competences [12], [17], [18], [23]. Teacher self-efficacy also affects students indirectly via the instructional strategies, planning and a willingness to try out new material and approaches to teaching a subject [19]. Teacher self-efficacy seems to be a rather strong predictor for the way teachers shape their teaching practices in order to foster students' motivation to learn [18] and relevant in education as well as other activities where skill development is processed [16].

The perceived self-efficacy of an individual refers to an identified strength [10] which is measured by degrees of certainty that one can perform specific tasks [25]. As a consequence of this, self-efficacy is typically measured directly by the subject of the study using a self-reporting scale. Preparation of a self-efficacy scale that properly measures the behavior in question requires careful design.

A self-efficacy scale consists of a number of statements (items) that express a personal position in relation to different skills and competences related to the subject in question. Respondents are asked to express to what extent they believe that they could do what is described in the statement based on their current level of knowledge. Answers are recorded on a Likert scale that in our case ranges from 1 to 7 . Statements are positively-worded and express actions rather than expressing 
TABLE II

COMPUTED AVERAGE AND DISCRIMINATION INDEX (D-INDEX) FOR ALL RESPONSES IN 74-STATEMENTS SELF-EFFICACY SCALE

\begin{tabular}{ccc||ccc||ccc} 
Statement & Average & d-index & Statement & Average & d-index & Statement & Average & d-index \\
\hline $\mathbf{1 1 1}$ & 6,58 & 0,13 & $\mathbf{2 5 2}$ & 5,52 & 0,21 & $\mathbf{4 2 4}$ & 5,21 & 0,37 \\
$\mathbf{1 1 2}$ & 6,50 & 0,16 & $\mathbf{2 5 3}$ & 6,02 & 0,19 & $\mathbf{4 2 5}$ & 4,77 & 0,38 \\
$\mathbf{1 1 3}$ & 5,84 & 0,27 & $\mathbf{2 5 4}$ & 5,55 & 0,19 & $\mathbf{4 2 6}$ & 5,64 & 0,31 \\
$\mathbf{1 1 4}$ & 6,47 & 0,17 & $\mathbf{2 6 1}$ & 4,27 & 0,35 & $\mathbf{4 3 1}$ & 5,05 & 0,13 \\
$\mathbf{1 1 5}$ & 6,08 & 0,23 & $\mathbf{2 6 2}$ & 3,93 & 0,34 & $\mathbf{4 3 2}$ & 5,13 & 0,18 \\
$\mathbf{1 2 1}$ & 5,71 & 0,23 & $\mathbf{2 6 3}$ & 4,29 & 0,35 & $\mathbf{4 3 3}$ & 5,34 & 0,24 \\
$\mathbf{1 2 2}$ & 5,71 & 0,23 & $\mathbf{3 1 1}$ & 5,95 & 0,31 & $\mathbf{4 4 1}$ & 4,57 & 0,28 \\
$\mathbf{1 2 3}$ & 5,97 & 0,25 & $\mathbf{3 1 2}$ & 5,83 & 0,36 & $\mathbf{4 4 2}$ & 4,19 & 0,35 \\
$\mathbf{1 3 1}$ & 6,70 & 0,13 & $\mathbf{3 1 3}$ & 5,68 & 0,33 & $\mathbf{4 4 3}$ & 4,21 & 0,28 \\
$\mathbf{1 3 2}$ & 6,56 & 0,18 & $\mathbf{3 2 1}$ & 5,64 & 0,37 & $\mathbf{5 1 1}$ & 4,65 & 0,39 \\
$\mathbf{1 3 3}$ & 6,17 & 0,21 & $\mathbf{3 2 2}$ & 5,76 & 0,32 & $\mathbf{5 1 2}$ & 5,36 & 0,35 \\
$\mathbf{1 3 4}$ & 5,81 & 0,28 & $\mathbf{3 3 1}$ & 5,66 & 0,34 & $\mathbf{5 1 3}$ & 4,65 & 0,44 \\
$\mathbf{2 1 1}$ & 4,70 & 0,36 & $\mathbf{3 3 2}$ & 4,97 & 0,49 & $\mathbf{5 1 4}$ & 5,64 & 0,34 \\
$\mathbf{2 1 2}$ & 4,49 & 0,31 & $\mathbf{3 4 1}$ & 3,72 & 0,47 & $\mathbf{5 1 5}$ & 6,46 & 0,19 \\
$\mathbf{2 1 3}$ & 5,71 & 0,31 & $\mathbf{3 4 2}$ & 3,55 & 0,46 & $\mathbf{5 2 1}$ & 5,36 & 0,43 \\
$\mathbf{2 1 4}$ & 5,79 & 0,32 & $\mathbf{3 4 3}$ & 3,24 & 0,46 & $\mathbf{5 2 2}$ & 5,42 & 0,38 \\
$\mathbf{2 2 1}$ & 6,26 & 0,24 & $\mathbf{3 4 4}$ & 3,50 & 0,47 & $\mathbf{5 2 3}$ & 5,13 & 0,34 \\
$\mathbf{2 2 2}$ & 6,20 & 0,28 & $\mathbf{3 4 5}$ & 4,32 & 0,55 & $\mathbf{5 3 1}$ & 4,07 & 0,47 \\
$\mathbf{2 2 3}$ & 5,76 & 0,31 & $\mathbf{3 5 1}$ & 4,19 & 0,47 & $\mathbf{5 3 2}$ & 5,71 & 0,38 \\
$\mathbf{2 3 1}$ & 5,74 & 0,34 & $\mathbf{4 1 1}$ & 4,21 & 0,38 & $\mathbf{5 3 3}$ & 5,69 & 0,32 \\
$\mathbf{2 3 2}$ & 6,23 & 0,30 & $\mathbf{4 1 2}$ & 5,64 & 0,32 & $\mathbf{5 4 1}$ & 4,51 & 0,43 \\
$\mathbf{2 4 1}$ & 5,76 & 0,44 & $\mathbf{4 1 3}$ & 3,76 & 0,42 & $\mathbf{5 4 2}$ & 5,83 & 0,28 \\
$\mathbf{2 4 2}$ & 5,94 & 0,33 & $\mathbf{4 2 1}$ & 5,11 & 0,35 & $\mathbf{5 4 3}$ & 5,88 & 0,28 \\
$\mathbf{2 4 3}$ & 6,25 & 0,26 & $\mathbf{4 2 2}$ & 4,93 & 0,40 & $\mathbf{5 4 4}$ & 5,95 & 0,24 \\
$\mathbf{2 5 1}$ & 6,29 & 0,22 & $\mathbf{4 2 3}$ & 5,39 & 0,37 & & &
\end{tabular}

specific knowledge. In the case of testing whether a person knows how to turn on a computer, the proper statement in a self-efficacy scale would be I could turn on a computer rather than I know how to turn on a computer.

There are several self-efficacy scales related to computing skills and digital competences, e.g. [3], [5], [13], [15], [20], [24]. The self-efficacy scale developed in this work specifically aim at teacher training and practicing teachers in K-9 schools in the context of computing and digital competences being added to national school curricula in a way that affects not only teachers in programming and computing, but most school subjects.

\section{SELF-EFFICACY IN DIGITAL COMPETENCES}

The self-efficacy scale in digital competences presented in this paper is based on the digital competence framework version 2.0 [4], summarized in Table I. The five main competence areas (Information and data literacy, Communication and collaboration, Digital content creation, Safety, and Problem solving) each include 3-6 competences. For each competence, the framework provides a set of examples of representative capabilities and skills.

As a first step in deriving a self-efficacy scale, we created a list of 74 statements to cover the competence areas and competences specified in DigiComp 2.0. The majority of the statements were directly inspired by examples provided by the framework. In addition to the items we extracted from the framework documents we formulated a small number of additional statements to provide specific coverage of competences and knowledge that our prior research and development work has identified are relevant for K-9 teachers. In doing so we have drawn on relevant working documents prepared during the background work associated with national curricula changes in Sweden and Finland, as well as our extensive experience of working together with teachers in in-service training in computational thinking. The goal of this initial phase was not to arrive at a certain number of statements, but rather to compile as comprehensive a list of statements as possible.

The final collection of statements was presented in chronological order and grouped based on the competence area to which each statement belonged. We associated a three digit code with ech statement, where the first digit represents the competence area, the second digit the specific competence and the last digit the statement number within that competence. This means that all statements that share a first digit belong to the same competence area, while two statements representing the same competence share the first two digits. This coding system provides the basis for assessing internal consistency and correlation between items that might be expected to be related to one another.

The 74-statement scale was converted into an on-line questionnaire, where teachers were asked to rate their own confidence in relation to each of the 74 statements on a scale of 1 (very uncertain) to 7 (very confident). In addition, we asked some background questions related to their teaching background and subjects. The scale was distributed online to teachers and school leaders in Finland and Sweden using a combination of social media, mailing lists and group communication tools. The test was administered in Swedish. English translations of the items are provided in this paper for readability. In total we received 107 responses, which were used for as the basis for the subsequent statistical analysis. The respondents were 81 females and 26 males with a teaching 
TABLE III

THE RESUlting 27 STATEMENTS

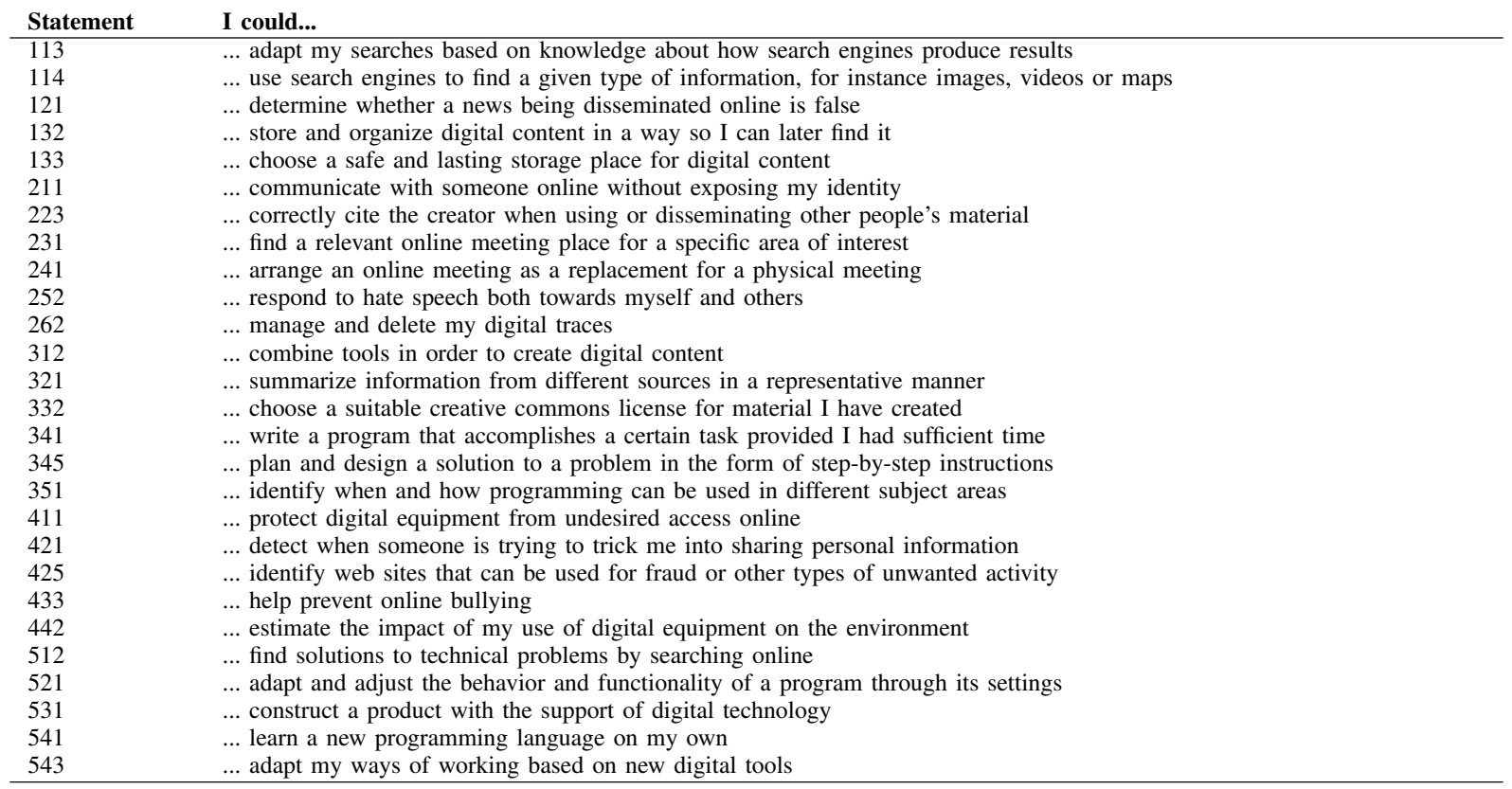

experience distribution as shown in figure 1.

Fig. 1. Distribution of teaching experience among respondents

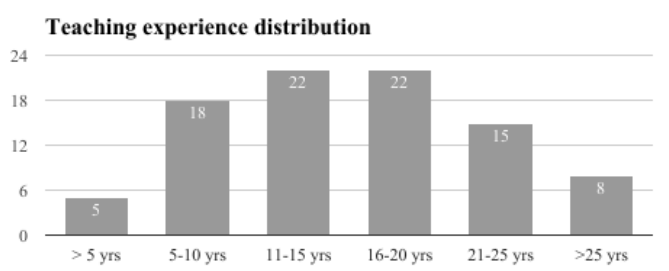

In phase two we computed item discrimination indexes (dindex) for all the statements as presented in table II. The dindex is a value between 0 and 1 where a higher number indicates that the statement has stronger ability to discriminate those respondents with a low self-efficacy from those with a high self-efficacy. Using the d-index as input, we identified key statements for each subtopic. Removal of redundant items, and items with poor discriminatory power allowed us to reduce the number of statements included in the scale from 74 to 24. The reduction of the number of items both increases the internal consistency of the underlying constructs and enhances the usability of the scale. Scales with large numbers of items typically suffer from lower participation and completion rates, a challenge that in our context has significant implications for the practical usability of the resulting instrument.

Finally we computed the cross correlation between all responses in order to identify statements that are strongly and weakly correlated to each other. Upon closer inspection we identified 3 statements that had a high discrimination index, but were just under the threshold used to select items in phase two. These three statements showed a low correlation with the statements that had been identified in phase two, justifying including these statements in the final set. After this additional analysis we arrived at a final self efficacy scale comprising 27 statements. These statements are presented in English translation in table III.

As a final check we extracted the statistical analysis of the pilot data associated with the statements comprising the final version of the scale. The internal correlation between these statements, based on the participating teachers' responses, is shown in figure 2. Cronbach's alfa for the scale items is 0,95 , which indicates a high internal consistency in our data set for the selected statements.

\section{DISCUSSION AND FUTURE WORK}

\section{A. Significance}

The development of a self-efficacy scale for digital competence is an important step in the systematic evaluation of capacity in the school system to meet the challenges associated with an increasing focus on digital competence and computational thinking in the school curriculum at all levels. The instrument developed in this research supports benchmarking of current capacity in the school sector, as well as providing a means to evaluate the impact of in service training of school teachers. Providing a quantifiable measure of teacher capacity also contributes to the process of collecting background data to inform policy makers at the state and national level as they prepare to meet the challenges associated with the introduction of new and revised curricula. 
Fig. 2. Correlation between answers to statements in reduced statements set.

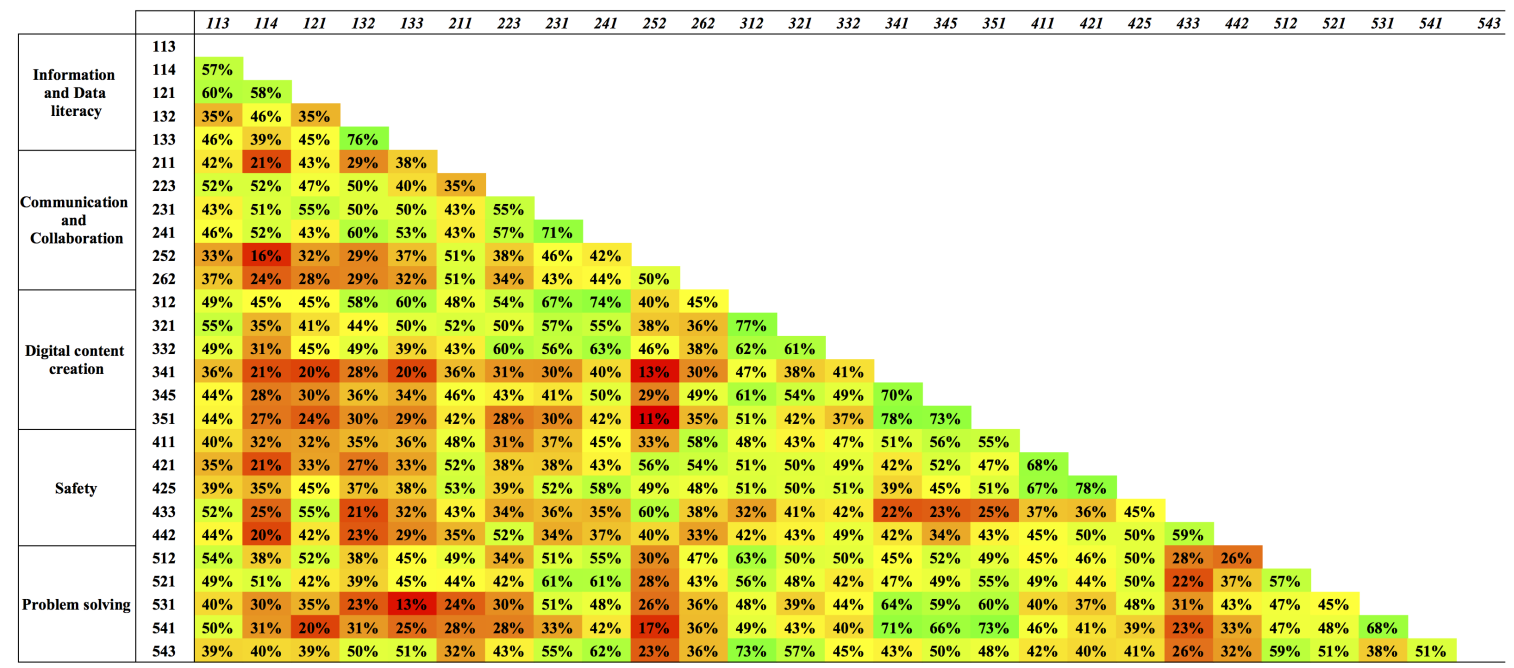

Previous research spanning more than 40 years demonstrates a positive correlation between teacher self-efficacy and teaching environment, student motivation and achievements. However, this is not the only advantage to be gained from improved self-efficacy, since self-efficacy is also shown to contribute to an overall increase in the well-being of teachers over time. Simply put, a teacher with a high self-efficacy in the subject he or she is teaching is more likely persist longer, provide a better teaching environment and not burn out as easily [23]. This in combination with introduction of digital competences over the entire school curricula provides another compelling reason to develop a tool to monitor self-efficacy in digital competences among K-9 teachers.

The self-efficacy scale described in this paper can be used over time to monitor the development of individuals' capability and sense of personal agency in regard to the use, integration and teaching of digital competences in school subjects. It can be used by individuals to track their own progress, but also by employers, strategists and policy makers to map needs for development efforts in certain areas.

\section{B. Reliability}

The analysis of the 107 responses collected during the development of the scale indicates that quite a few of the respondents had high values in many competence areas. This results implies that the sample of teachers responding to our pilot survey may not representative of the teacher population in general. Our survey distribution approach through social media groups and mailing lists for school teachers was more likely to evoke responses from enthusiastic teachers with an interest in digital competence and computational thinking. This is, however, not a threat to the validity of our statistical analysis or method of selecting the items to be included in the final instrument. The main goal of the online questionnaire was to collect a sufficient number of responses to make it possible for us to decrease the number of statements and arrive at a representative set of statements through statistical analysis.

When looking at responses with a more heterogeneous set of values (both high and low values), the first competence area (Information and data literacy) appears to be the one the respondents, in general, felt most secure with. This can be seen as an expected and natural result, as collecting, evaluating and managing data are activities most teachers already engage in. Others have also arrived at similar findings, for instance when studying K-9 teachers' engagement in computational thinking practices [11].

\section{Future work}

The next stage in our research is to use the instrument presented in this paper to evaluate trainee teachers in teacher training departments, in-service teachers in the context of professional development activities and in different school settings in Finland, Sweden and Lithuania. These studies will commence in the Autumn of 2017 and continue during the first year of the new curriculum.

We are particularly interested in how our scale can be applied to studying the development of digital competences among individuals who are, to some extent, forced to engage with the development of digital competences, e.g. teachers in non-technical subjects where digital competences have now been mandated in the curriculum. In addition, we plan to investigate the potential of using the instrument as the basis for creating new versions suited for children. We have also considered using the scale to monitor digital competences self-efficacy among, and educational efforts for, seniors who are placed in situations where they are expected to use new technologies, and develop the skills and competences needed to meet the increasing digitalization of society. 


\section{REFERENCES}

[1] Anja Balanskat and Katja Engelhardt. Computing our future. computer programming and coding. priorities, school curricula and initiatives across europe. Technical report, 2015.

[2] Albert Bandura. Self-efficacy: The exercise of control. Macmillan, 1997.

[3] Vehbi Celik and Etem Yesilyurt. Attitudes to technology, perceived computer self-efficacy and computer anxiety as predictors of computer supported education. Computers \& Education, 60(1):148 - 158, 2013.

[4] EU Commission. Digital Competence Framework for Educators (DigCompEdu). https://ec.europa.eu/jrc/sites/jrcsh/files/digcompedu_leaflet_ final.pdf. Online, accessed April 22, 2017.

[5] Deborah R. Compeau and Christopher A. Higgins. Computer selfefficacy: Development of a measure and initial test. MIS Quarterly, 19(2):189-211, 1995.

[6] P Eachus and S Cassidy. Developing the computer self-efficacy (cse) scale: Investigating the relationship between cse, gender and experience with computers. Retrieved April, 24:1999, 1999.

[7] Finnish National Agency for Education. Grunderna för läroplanen för den grundläggande utbildningen. http://www.oph.fi/download/166434_ grunderna_for_laroplanen_verkkojulkaisu.pdf, 2014. Föreskrifter och anvisningar 2014:96.

[8] Finnish National Agency for Education. Progetiger programme 2015-2017. media.voog.com/0000/0034/3577/files/Programm\% 20ProgeTiiger\%202015_2017eng.pdf, 2015.

[9] Fredrik Heintz, Linda Mannila, and Tommy Färnqvist. A review of models for introducing computational thinking, computer science and computing in k-12 education. IEEE.

[10] Mavra Kear. Concept analysis of self-efficacy. Graduate research in nursing, 2(2):1-7, 2000.

[11] Linda Mannila, Valentina Dagiene, Barbara Demo, Natasa Grgurina, Claudio Mirolo, Lennart Rolandsson, and Amber Settle. Computational thinking in k-9 education. In Proceedings of the Working Group Reports of the 2014 on Innovation \&\#38; Technology in Computer Science Education Conference, ITiCSE-WGR '14, pages 1-29, New York, NY, USA, 2014. ACM.

[12] William P Moore and Mary E Esselman. Exploring the context of teacher efficacy: The role of achievement and climate. 1994

[13] Christine A. Murphy, Delphine Coover, and Steven V. Owen. Development and validation of the computer self-efficacy scale. Educational and Psychological Measurement, 49(4):893-899, 1989.

[14] Internation Society of Technology in Education. Iste teacher standards. http://www.iste.org/standards/standards/standards-for-teachers, 2017.
[15] Vennila Ramalingam, Deborah LaBelle, and Susan Wiedenbeck. Selfefficacy and mental models in learning to program. SIGCSE Bull., 36(3):171-175, June 2004.

[16] Vennila Ramalingam and Susan Wiedenbeck. Development and validation of scores on a computer programming self-efficacy scale and group analyses of novice programmer self-efficacy. Journal of Educational Computing Research, 19(4):367-381, 1998.

[17] John A Ross, Anne Hogaboam-Gray, and Lynne Hannay. Effects of teacher efficacy on computer skills and computer cognitions of canadian students in grades k-3. The Elementary School Journal, 102(2):141-156, 2001.

[18] Erik E.J. Thoonen, Peter J.C. Sleegers, Thea T.D. Peetsma, and Frans J. Oort. Can teachers motivate students to learn? Educational Studies, 37(3):345-360, 2011.

[19] Megan Tschannen-Moran and Anita Woolfolk Hoy. Teacher efficacy: Capturing an elusive construct. Teaching and teacher education, 17(7):783-805, 2001.

[20] vehbiturel@yahoo.co.uk TUREL, Vehbi1. Teachers' computer selfefficacy and their use of educational technology. Turkish Online Journal of Distance Education (TOJDE), 15(4):130 - 149, 2014.

[21] Ellen L. Usher and Frank Pajares. Self-efficacy for self-regulated learning. Educational and Psychological Measurement, 68(3):443-463, 2008.

[22] Riina Vuorikari, Yves Punie, Stephanie Carretero, and Lieve Van den Brande. DigComp 2.0: The Digital Competence Framework for Citizens. https://ec.europa.eu/jrc/sites/jrcsh/files/digcompedu_leaflet_final. pdf, 2016. Online, accessed April 22, 2017.

[23] Marjolein Zee and Helma M. Y. Koomen. Teacher self-efficacy and its effects on classroom processes, student academic adjustment, and teacher well-being: A synthesis of 40 years of research. Review of Educational Research, 86(4):981-1015, 2016.

[24] Yixin Zhang and Sue Espinoza. Relationships among computer selfefficacy, attitudes toward computers, and desirability of learning computing skills. Journal of Research on Computing in Education, 30(4):420, Summer 1998. Copyright - Copyright International Society for Technology in Education Summer 1998; Last updated - 2014-05-21.

[25] Barry J Zimmerman and Albert Bandura. Self-efficacy and educational development. Self-efficacy in changing societies, pages 202-231, 1995. 